\title{
Hidden and forbidden: conceptualising dark knowledge.
}

\author{
BURNETT, S. and LLOYD, A.
}

2020

This author accepted manuscript is deposited under a Creative Commons Attribution Non-commercial 4.0 International (CC BY-NC) licence. This means that anyone may distribute, adapt, and build upon the work for non-commercial purposes, subject to full attribution. If you wish to use this manuscript for commercial purposes, please contact permissions@emerald.com 


\section{Emerald Journal of}

\section{Hidden and Forbidden: Conceptualising Dark Knowledge}

\begin{tabular}{|r|l|}
\hline Journal: & Journal of Documentation \\
\hline Manuscript ID & JD-12-2019-0234.R2 \\
\hline Manuscript Type: & Article \\
\hline Keywords: & $\begin{array}{l}\text { Ethics, Epistemology, Knowledge frameworks, Behaviour, Ethnic Groups, } \\
\text { Information, Individual behavior }\end{array}$ \\
\hline \multicolumn{2}{l}{} \\
\end{tabular}

SCHOLARONE $^{\text {Tw }}$

Manuscripts 


\section{Hidden and Forbidden: Conceptualising Dark Knowledge}

\section{Purpose}

The purpose of this paper is to introduce the concept of Dark Knowledge, an epistemology which acknowledges both alternative knowledges and ways of knowing which are cognizant of the moral and ethical positioning of each.

\section{Design/methodology/approach}

This is a conceptual paper which uses existing relevant literatures to develop the work. The paper uses a four-stage literature search process, and draws upon a range of disciplines including philosophy, computer science and information management to underpin the evolution of the concept.

\section{Findings}

As a conceptual paper, no empirical findings are presented. Instead, the paper presents an embryonic model of Dark Knowledge, and identifies a number of characteristics which may be used to explore the concept in more detail.

\section{Research limitations/implications}

There is a clear need to develop a body of empirical work adding to the theoretical perspectives presented in this paper. It is anticipated that this paper will provide one of the cornerstones for future studies in this area.

\section{Originality/value}

The paper makes an original contribution to the study of information behaviours, practices and epistemology.

\section{Keywords}

Knowledge, Morality, Ethics, Epistemology, Refugees 
Dedicated to the memory of Dorothy Anne Burnett (05/06/38 - 21/03/20)

\section{Introducing Dark Knowledge}

In this paper we attempt to bring the concept of Dark Knowledge into the light. Dark Knowledge is knowledge that may be hidden (from power or positioned to enable power) by its custodians to avoid revealing its purpose or value, or forbidden because its acquisition, possession and application may be immoral, unethical or illegal.

Evidence of the concept has been present since time immemorial. Johnson (1996) suggests that: 'The idea of forbidden knowledge comes to us from the biblical story of the Garden of Eden and the knowledge forbidden to Adam and Eve by God', chimes with Shattuck's (1996) view that '[p]roverbs in every language tell us that it is possible to know too much for our own good. Many great myths and legends explore the perils of knowledge.' In Greek mythology, Prometheus steals fire and knowledge of metalworking from the gods and gives these to mankind. His punishment for this crime is to be being chained to a mountain, and his flesh consumed by an eagle, only to regrow and be consumed again ad infinitum.

In literature, Tolkein's character Sauron invests the 'One Ring' with dark knowledge and powers of domination and control. This theme of dark knowledge and power is also extended to other of Tolkein's characters, notably Saruman, whose description in 'The Fellowship of the Ring' leads Stadtwald (2016) to comment: '...it reveals that he has extensive knowledge of ring lore, and therefore how to obtain and use power.' Dark Knowledge is also threaded through stories of spycraft and espionage (e.g. Bauer, 2013; West, 2016) and has the potential to marginalise, exclude, isolate and 'other' people or communities who rationalise acceptance of this form of epistemic knowledge and thus set themselves apart from the socially acceptable form of knowledge.

Paradoxically, despite our current era being defined by its relationships with data, information and knowledge, and extensive coverage of the concept of knowledge itself (e.g. Polanyi, 1966), the concept of Dark Knowledge has largely eluded attention, specifically in the field of library and information science. For example, within knowledge management much of the research focus has been on the application of tools, processes and techniques to facilitate the management of organizational knowledge within the private, public and third sectors. It is taken as read that, as Kempner et al (2011, p.467) suggest, the principle of 'the open pursuit of knowledge is ipso facto good', and at no point does the field reflect on the morality of the acquisition or application of knowledge.

This work is also a departure from more mainstream information research. Kari and Hartel (2007) suggest that 'The majority of information research has focused on occupational information phenomena.' This paper acknowledges Kari and Hartel's view of information research as focussing predominantly on the quotidian and the workplace. While we do not seek to critique this view, we do consciously seek to present an extension to our view of knowledge, and as such aim to contribute meaningfully to the field, again acknowledging the views of Kari and Hartel: 'The probability of discovering something truly novel would be higher if information scholars wishing to pursue innovative research went beyond the everyday realm, 
which has already become so well known from the angle of information phenomena.'(2007, p 1132).

This paper presents an emerging conceptualisation of the concept of Dark Knowledge in information studies. In this paper, we present Dark Knowledge as an alternative epistemology in which we acknowledge both alternative knowledges and ways of knowing which are cognizant of the moral and ethical positioning of both. In doing so, we identify and discuss the discourses which support these perspectives. Using a socio-theoretical perspective, we use 'dark' as a blanket term to acknowledge the purposeful impenetrability or obfuscation of knowledge, and to suggest potentially unethical or immoral dimensions of knowledge which we will discuss within this paper. In relation to information studies, our interest in this topic not only considers the nature of knowledge itself, but also how that knowledge may be acquired and ultimately applied.

For the purposes of this paper, we use the term 'Light Knowledge' as the antithesis of Dark Knowledge. We define Light Knowledge as socially accepted knowledge, which is acquired and used within established legal, ethical and moral boundaries. For example, knowing how to buy illegal drugs or firearms from the Dark Web could be considered a form of Dark Knowledge (Bancroft and Reid, 2016) as it utilizes knowledge of illegal goods, and knowledge of how these may be acquired. Similarly knowing how to 'game' a system or process, for example, insider stock market trading (Werhane, 1989) for personal gain could also fall under this umbrella term as could knowing how to bypass rules and regulations associated with movement to secure passage to a safer country.

As societal ethical stances change over time, the knowledges we currently perceive as light or dark may also change. For example, buying cannabis online is currently illegal in the UK (so performing this task would be an application of Dark Knowledge). However, if cannabis were to be legalized, then this would no longer be Dark Knowledge. These knowledges may be shielded from view to obscure ownership or usage in a range of ways, for example the use of the Darknet or the application of tricks of the trade or workarounds (Alter, 2014) from which strategic advantage can be obtained or the deliberate dissemination of misinformation as a mechanism for hiding real ambitions.

From our understanding of these related topics, we determine two characteristics which are reflected in our definition of Dark Knowledge. We use dark as an adjective to describe the states of knowledge. We propose that dark is a useful term to convey the sense that knowledge may be 'dark' in two ways. Firstly, that knowledge may be dark in the sense that it is somehow illicit, and that its possession may hint at an act or acts of civil disobedience or resistance. In that sense, knowledge may be intentionally kept dark to reduce its discoverability by authoritarian agencies, or indeed by the general public. In this sense, we highlight the desire to keep knowledge in the dark hidden from view. Secondly, the ethics of both the ownership and utilisation of knowledge is further conveyed by the use of the term 'dark'. This knowledge needs to be kept hidden because of its moral, ethical or legal ambiguity. We use the terms 'hidden' and 'forbidden' to emphasise both this dualistic definition we have developed for Dark Knowledge, and also to help explain the relationship which exists between power and knowledge. 


\section{Methodology}

This work has been developed using a search and review of relevant literatures. Given the relative novelty of the topic and its lack of coverage within the information studies literatures in particular, the authors used an iterative four-stage process to identify published materials of relevance to the topic of Dark Knowledge (see Figure 1).

\section{[INSERT FIGURE 1 HERE]}

\section{Figure 1: Literature search process}

The search and review were not intended to be comprehensive, but to provide sufficient materials for the authors to present their nascent conceptualisation of Dark Knowledge. Further iterations of the process will be used to refine and expand the work as it develops over time and enable the authors to approach and establish saturation.

The first stage of the search was a general web-based search and browse to begin to identify key terms related to the subject. This initial search produced several terms (see Table 1):

\section{[INSERT TABLE 1 HERE]}

\section{Table 1: Key search terms}

Broadly, these terms relate to the context within which Dark Knowledge can be found, related topics, or characteristics of the concept itself. The results of this preliminary search were used to produce a combination of Boolean logic search terms which were subsequently used in the second stage of the search and review process: a search of key databases (including Web of Science, Scopus and Google Scholar).

Once the search of key databases was complete, the authors used the results of the second stage to undertake a backward reference search. Also known by other terms including backward citation searching, descendancy searching and citation tracing, backward chain searching uses the lists of references provided in publications (identified in Stage 2) to identify relevant publications. This approach is particularly useful in developing an understanding of the genesis of a topic, how it has developed over time and who the key authors and works are within a given discipline. These reference lists were scanned for relevant publications, and where possible, those publications were accessed and included within the literature review.

Lastly, a forward reference search (or ascendancy search) was conducted. Forward reference searching identifies works which have cited the initial publication. The purpose of this stage was to identify the most recent works relevant to the topic. The 
results of these searches were reviewed thematically and are presented throughout the paper.

\section{Dark Research}

In recent years we have seen a number of socio-environmental movements acknowledging or utilising the term 'dark' to describe a specific aspect of their current activities. Terms such as 'dark money' (Mayer, 2017), and the 'dark web' (Chen, 2011) have emerged, alluding to a potentially sinister or hidden aspect of a topic. Linstead et al (2014) provide a useful introduction to the sphere of dark research in the context of organizational research. The authors propose that while dark side behaviours may be challenging to observe, and when they are observed 'may be negative, abnormal and even deviant from an organizational perspective', they note that (like Dark Knowledge) 'when observed from different vantage points and with different tools these behaviours may appear normal, rational and purposeful' (2014, p.168).

Although a recently perceived phenomenon, the roots of the dark research builds on the work of Foucault, which in turn resonates with the transdisciplinary field of surveillance studies (Wood, 2007). In 'Discipline and Punish', Foucault (2012, p.308) is explicit in his aim, the sentiment of which has resonance within this paper: 'must serve as a historical background to various studies of the power of normalization and the formation of knowledge in modern society'. Indeed, the topic of Dark Knowledge is ultimately and fundamentally Foucauldian in nature, considering as it does the dynamics which exist between knowledge and power and the production and privileging of discourse. Foucault provides one of the first allusions to Dark Knowledge ('obscure' in his account) in relation to economic transformation at the end of the $18^{\text {th }}$ Century:

'A money reform, a banking custom, a trade practice can all be rationalized, can all develop, maintain themselves or disappear according to appropriate forms; they are all based upon a certain ground of knowledge: an obscure knowledge that does not manifest itself for its own sake in a discourse, but whose necessities are exactly the same as for abstract theories or speculations without apparent relation to reality. In any given culture and at any given moment, there is always only one episteme that defines the conditions of possibility of all knowledge, whether expressed in a theory or silently invested in a practice' (Foucault, 2005, pp.182-3).

Foucault highlights a perspective which is echoed in this paper, namely that within a given setting knowledges exist which are not readily apparent, but yet are still significant within the contexts they are observed. Consequently a binary between dark and light knowledges and ways of knowing each can be seen to exist. This view echoes Lloyd (2014, p.99), who suggests that 'Non-normative information sources are trickier to access and capture because they reflect the insider, or internal, view that represents the social and embodied aspects that shape performance and ways of knowing.' She goes on to state that these insider views are 'founded on ways of knowing that are articulated through collective action and the development of intersubjective agreement about where knowledge resides and what knowledges are important.' 
Both Foucault's and Lloyd's perspectives underpin the view of Dark Knowledge as something (either purposefully or inadvertently) hidden. In working with this concept, we note synergies between Dark Knowledge and the work of Chatman (1996), who explores the concept of secrecy and deception and the situational relevance as instrumental to explaining information poverty. According to Chatman's research, secrecy may emerge when people see themselves as outsiders and feel the need to guard and protect themselves against unwanted attention. While deception emerges as disingenuous representation - people who deceive are 'play acting' in an attempt to distort their personal reality. The concept of situational relevance proposed by Chatman (and informed by Dervin's theory of sense-making, 1976) highlights the importance of context for meaning making. Consequently, knowledge may also be viewed as Dark by the wider community or similarly by those on the outside, if it is secretive, or deceptive creating the conditions for an 'insider/outsider' view.

The most important contribution that Chatman's work makes to our emerging conceptualisation is the through the idea of control. Dark knowledge is not just an ontological acceptance of knowledges but is also epistemological due to the effect of control on the availability of Dark Knowledge and how that control is enabled or constrained via ways of knowing or activities such as secrecy or deception. This point extends Dark Knowledge beyond forbidden or hidden knowledge because it acknowledges the power and agency that comes through the intentional acceptance of other forms of knowledge and ways of knowing. Chatman suggests that:

" concealed information is intended as a separation mechanism in which a person or select group of persons view themselves as ultimate insiders" (1996, p.195)

However, the acknowledgement of darkness as a concept which encompasses a variety of activities (as discussed above and below) is given a rather more negative view by Griffin, O'Leary-Kelly and Pritchard (2004). These authors suggest that there are two broad categories of dark practices in organisational contexts: those that harm individuals, and those that harm organisations. They propose that the dark side consists of: 'situations in which people hurt other people, injustices are perpetuated and magnified, and the pursuits of wealth, power or revenge lead people to behaviours that others can only see as unethical, illegal, despicable, or reprehensible' (Griffin, O’Leary-Kelly and Pritchard, 2004, p.xv).

This is a departure from our perspective which proposes that darkness may not necessarily be injurious to either individuals or organisations, but that it may simply refer to knowledge that is hidden to avoid detection. This broader conceptualisation appears to resonate with a growing sense of ambiguity regarding morality and ethics in public spheres, as exemplified by the ongoing 'fake news' and misinformation debates (e.g. Tandoc Jr, 2018).

There are however numerous examples which can be used to highlight the more sinister aspects of Dark Knowledge and emphasise the distinction between the application for morally corrupt motives, and those for good, for example the case of Dr Harold Shipman (Smith, 2004). Shipman, an English general practitioner, is widely believed to be one of the most prolific serial killers in history, with an estimated body count of around 250 people, mostly elderly women. Shipman used his 
medical knowledge, position and expertise to administer fatal doses of diamorphine, sign patients' death certificates, and falsify medical records.

In the context of computing, Batory et al (2013) see Dark Knowledge as akin to Dark Matter due to its lack of observability. However, Batory et al focus more specifically on the highly tacit nature of Dark Knowledge and suggest that it also has a limited temporal dimension within which it is used and then subsequently forgotten: 'Dark knowledge is fleeting and temporally 'unstable', i.e., only exists and becomes available at the moment of practice (Bonner and Lloyd, 2011). 'Programmers may know it one day and forget it the next. It is not present in source code. Yet we know Dark Knowledge exists, because with it we can explain program designs' (Batory et al, 2013, p.1). Indeed, they suggest that Dark Knowledge is synonymous with tacit knowledge. However we extend Batory et al's conceptualisation of Dark Knowledge to include explicit knowledge.

In our conceptualisation, we propose that Dark Knowledge may be hidden in explicit as well as tacit forms. For example in relation to occult knowledge, Baskin (2015) notes that: 'Modern occultists maintain that the most profound secrets of the Cabala are not recorded in accessible form but are passed on by word of mouth to those who are worthy of them or embodied in ancient documents which have never left the hands of initiates.' While Batory et al make a strong case for Dark Knowledge, they acknowledge that Baxter (1992) initially proposed the term in relation to the need to make tacit knowledge explicit in relation to software design.

There are a number of other mentions of Dark Knowledge from the computing domain which broadly relate to neural networks. Balan et al (2015, p.3438) suggest that the term Dark Knowledge was coined by Hinton, Vinyals and Dean (2015) 'to represent the information which is "hidden" inside the teacher network, and which can then be distilled into the student.' Again, Hinton et al's use of the term can be seen to be closely related to Batory's (2013) usage.

Despite the clear interest in the concept of Dark Knowledge, there remains little or no attempt to clearly conceptualise it beyond brief definitions. Jeschke et al (2019) present their own view of Dark Knowledge (or 'knowledge in the dark') but they posit that Dark Knowledge is 'the gap between real and potential knowledge' (see Figure 2).

\section{[INSERT FIGURE 2 HERE]}

\section{Figure 2: Knowledge in the Dark (Jeschke et al (2019))}

In this context, they propose that Dark Knowledge is in fact 'a particular part of ignorance for which a specific term (and definition) has been lacking thus far.' While clearly related to this work through its use of nomenclature, Jenschke et al's work diverges significantly as it positions dark knowledge as a form of incomplete or inaccurate data or information, rather than viewing dark knowledge from an ethical or moral stance as we do in this work.

Smith (2018) draws upon Weinstein's concept of the 'Intellectual Dark Web' (Weiss, 2018), which posits that there exists (or should exist) a neutral information space in 
which controversial and even dangerous concepts may be examined, free from recourse. Naturally, the Intellectual Dark Web is not without its critics, and despite keen interest in the topic, Smith does not delve into the concept of Dark Knowledge beyond the title of the article itself, so while Dark Knowledge is being presented as a useful term to discuss concepts around hidden knowledge, it lacks a robust definition, and a more detailed examination of its nature.

The use of the term dark takes a more sinister turn in its application to the Internet, but similarly alludes to need or desire to hide. The 'Dark Web', a term used to describe parts of the internet only accessible with specific software tools, is defined by Chen et al (2008, p.1347) as: 'the portion of the World Wide Web used to help achieve the sinister objectives of terrorists and extremists'. Jardine (2018, p.2825) however adopts a somewhat more balanced approach in her assessment, which, while acknowledging the use of the Dark Web as a facilitating platform for criminality, may also be used for less nefarious purposes: ' ...ordinary people can use anonymitygranting technologies to protect their privacy from government agencies, political opponents, trolls, data- hungry corporations and even Internet service providers.' Jardine thus moves the discussion away from a simple binary positioning around the use of the Dark Web, and hints at the need for a more nuanced approach in which individuals may seek to protect themselves and their data.

While these terms may appear to be only loosely connected, they are united in their acknowledgement of significant societal issues concerning privacy, legitimacy, freedom and censorship, and acknowledge the tensions which exist around personal anonymity, cultural identity, resistance and surveillance.

\section{From Knowledge to Enacting Dark Knowledge}

Much has been made of the challenges in defining knowledge and of the distinctions between related concepts like data, information and wisdom (DIKW). Notably Jeschke et al (2019) use a form of this model to underpin their work on 'knowledge in the dark'. However, models such as DIKW have been posited by writers and researchers in and around information science, however these have been widely critiqued because they lack sufficient distinction between the concepts to allow for objective definition or because they are in effect comparing apples with oranges (Zins, 2007). It is evident from the literature that not only is it difficult to define knowledge per se, but also in attempting to define it in relation to other elements of a hierarchy. What is lacking in these definitions is an explicit appreciation of the highly contextual nature of knowledge.

We suggest that the highly tacit nature of hidden knowledge lends itself to the concept of Dark Knowledge. Many of the attempts at the classification of the forms of knowledge can be seen to be based heavily on the work of Polanyi (although Reber (1995, p.15) suggests that the work on 'tacit' knowledge may be traced back to work conducted in the $19^{\text {th }}$ century). Critically, Polanyi proposes the concept of 'tacit knowledge' whereby knowledge, although possessed by an individual cannot be articulated to others. Polyani (1966, p.4) declared that "I shall reconsider human knowledge by starting from the fact that we can know more than we can tell.' (Polanyi, 1966, p.4). Polanyi proposes that not all knowledge can be made explicit, and as such the knowledge an individual makes explicit is only a subset of their tacit 
knowledge. This point is significant in relation to Dark Knowledge as it points to the resistance or reluctance to making knowledge explicit in order to avoid its detection. We use Polanyi's seminal work (1966) on the nature of knowledge to reinforce our argument that Dark Knowledge may be purposefully hidden. Therefore, hiding knowledge may be achieved (at least in part) by avoiding its codification. In other words, by converting from tacit to explicit, knowledge becomes 'discoverable'. The use of 'tacit' to describe knowledge is highly apposite within the context of this work, as it specifically implies the secret (and silent) nature of hidden knowledge.

Blackler (1995) created a typology of knowledge which not is not founded on commodification and which moves the concept of knowledge towards 'knowing;' described by him as "mediated situated provisional pragmatic and contested' (p.1021, 1995). Blackler argues that 'when we explore knowledge or knowing, we focus on culturally localised systems'. This typology splits knowing into categories described by Blackler as embodied, encoded, enculturated, embedded and embrained knowledges that were inherent in the enactment of organisational learning. Embodied knowledges (action oriented and only partially explicit); enculturated knowledges (inherent in developing mutual/shared understanding; encoded knowledges, where is knowing is connected to the signs and symbols of practice. Embedded knowledge describes the connections, operations and systems of an organisation and embrained knowledges which reference the abstracts elements of knowledge and ways of knowing. While this work has been revised and amended by more recent authors, we find this original typology useful when considering the categories that might define the shape of Dark Knowledge and its enactment thus giving more concrete ways to describe how this form of knowledge and ways of knowing may emerge in localised and specific practices.

In relation to knowledge, we posit (in close agreement with Berger and Luckman (1991) that knowledge is socially constructed. They argue that the sociology of knowledge "must concern itself with everything that passes for "knowledge" in society' (p.27). This paper is a direct acknowledgement that societally, we have omitted the presence of Dark Knowledge from our studies into knowledge, and that its recognition alone contributes to an expansion of our worldview. Berger and Luckman also highlight the highly contextual nature of knowledge which we also emphasise here. For example, they suggest that society's interest in the topics of 'reality' and knowledge' is initially justified due to social relativity: 'What is 'real' to a Tibetan monk may not be 'real' to an American businessman. The 'knowledge' of the criminal' differs from the 'knowledge' of the criminologist.' (Berger and Luckman1991, p.15). However, Berger and Luckman do not consider the associated ethical and moral issues of Dark Knowledge which we explore here. In addition, we suggest that existing definitions of both knowledge economies and knowledge societies do not acknowledge the role of knowledge within informal 'grey' economies, or indeed illegal 'black' economies (Emi et al, 2019).

In the context of this discussion, we define enactment as the operationalisation and performance of knowledge or ways of knowing. Enactment is most closely associated with the knowledge process of knowledge use/application. However, knowledge processes have not previously considered the ethical/moral dimensions associated with knowledge processes. Enactment is closely related to embodiment in which the performance is portrayed by the actor. Embodiment is the personification of 
enactment. Thus, a police officer may use knowledge about breaking into a house to enact preventative measures to protect property owners from burglars. It is in effect, the modus operandi of knowledge agents. It is embodied within the norms, customs, practices, language and dress of the police officers. However, Martzoukou and Burnett (2018) highlight the highly contextual nature of this embodiment, as the experiences of refugees in Syria do not share this (westernised) view of police officers as protectors of the innocent. Therefore, there is a paradox in the portrayal of officers as operating to uphold the law (as evidenced by their language, dress, etc.), and the behaviours and practices which officers adopt which do not adhere to this image.

\section{Forbidden Knowledge}

Perhaps the most notable characteristic of Dark Knowledge is that it may be forbidden. Shattuck proposes six categories of forbidden knowledge (1996, p.327):

- Inaccessible, unattainable knowledge

- Knowledge prohibited by divine, religious, moral, or secular authority

- Dangerous, destructive, or unwelcome knowledge

- Fragile, delicate knowledge

- Knowledge double-bound

- Ambiguous knowledge

For the purposes of this paper, we focus predominantly on the second and third categories. Forbidden knowledge has been defined in the literature (Kempner, Merz and Bosk, 2011, p.476) as 'knowledge that is too sensitive, dangerous or taboo to produce'. This means knowledge that is in opposition to societal norms and values, and is deemed to be harmful to society in general. As Kempner et al, suggest:

'Forbidden knowledge embodies the idea that there are things that we should not know. Knowledge may be forbidden because it can only be obtained through unacceptable means, such as human experiments conducted by the Nazis; knowledge may be considered too dangerous, as with weapons of mass destruction or research on sexual practices that undermine social norms; and knowledge may be prohibited by religious, moral, or secular authority, exemplified by human cloning.' (Kempner et al, 2005, p.854).

Societal boundaries are present which surround forbidden knowledge. Ongoing attempts by governmental and religious institutions to curtail public access to content include 'The Index Librorum Prohibitorum' last produced by the Catholic Church in 1948. Johnson (1996, p.202) helpfully provides specific reasons as to why knowledge may be forbidden in the first place, which she describes as 'transformative' (i.e. that knowledge will change how we behave, possibly for the worse), and 'consequentialist' (i.e. that the possible negative effects of possessing knowledge are enough to lead to it being forbidden).

Other examples of forbidden knowledge exist in explicit forms, and their availability has become more straightforward given their presence on the internet, and through peer content sharing platforms. The well-known 'Anarchist Cookbook' is one such example (Powell, 1971). Originally published in 1971 and closely related to the US counterculture movement, the book contains detailed instructions on explosive and 
illicit drug manufacture, as well as rudimentary hacking techniques. It is treated as contraband in many countries because of the ideology it espouses, and the operational elements it contains (indeed the author later renounced the work). While we can argue that the content is not in itself socially detrimental, the operationalisation and application of the knowledge it contains may be viewed as such.

This debate echoes Rehmann-Sutter's term 'Frankensteinian Knowledge' (1996). He proposes that 'Scientific knowledge is experimental knowledge. Such knowledge can be seen as "forbidden," either because the experiments leading to that knowledge are seen as immoral, or because interventions made possible by that knowledge could be morally offensive.' This perspective closely relates to Johnson's (1996) view that 'If there is only one way to acquire knowledge, then the knowledge may be forbidden, but only because of what it takes to get it, not because of the character or nature of the knowledge.'

This distinction between knowing, acquiring and applying knowledge is also present in the work of Johnson (1996) who proposes two distinctions which are ever-present within the debates around scientific autonomy and forbidden knowledge, and are useful for aiding understanding of this concept more generally. Johnson's first distinction emphasises the significance of the knowledge acquisition process. 'The distinction allows us to see how the methods used in acquiring knowledge might justifiably be forbidden, while the knowledge is not. If there is only one way to acquire knowledge, then the knowledge may be forbidden, but only because of what it takes to get it, not because of the character or nature of the knowledge' (Johnson, 1996, p.198). An echo of this distinction is presented by Kempner et al (2011) in their consideration of the knowledge gained by Nazi experimentation.

Johnson's second distinction relates to the application of knowledge, and knowledge itself: 'On the basis of this distinction, it is then argued that while a technology might justifiably be forbidden (e.g., nuclear weapons), the knowledge used in developing it could not justifiably be forbidden. Since it is the uses of the knowledge that are dangerous, not the knowledge itself, the uses may be constrained, not the knowledge.'

These distinctions are summarised by Kempner, Merz and Bosk (2011) who state that knowledge may be forbidden due to the method of its acquisition or be prohibited because it does not adequately separate the 'sacred and the profane' (p.478). In effect, Kempner et al suggest that there is knowledge which humans should not know, and that this is a form of forbidden knowledge.

This second distinction moves the debate around forbidden knowledge away from the methods by which knowledge may be acquired, and onto the subject of the knowledge itself. Shattuck (1996) explores this idea in relation to the development of the atomic bomb, and notes Oppenheimer's questioning of its manufacture. However, forbidden knowledge is not only scientific in nature. We suggest that close to Shattuck's second category of forbidden knowledge (knowledge prohibited by divine, religious, moral, or secular authority) is our characteristic of hidden knowledge. 


\section{Hidden knowledge}

While most of the examples of Dark Knowledge discussed thus far fall into Shattuck's category of dangerous knowledge, debates around esoteric knowledge focus more on the second category: prohibited knowledge. Into this category fall topics such as witchcraft and black magic, long considered to be taboo from a Western Judao-Christian perspective. However, as Shattuck notes, '[t]hese ancient and modern prohibitions on particular areas of knowledge sometimes stimulate human curiosity more than they dampen it.' (1996, p.330). Similarly, Kempner, Merz and Bosk (2011) argue that existing debates concerning forbidden knowledge are often rooted in the idea that forbidden knowledge is static and as such do not attend to issues of power, agency, institutions or culture. Given this, they go on to propose that 'forbidden knowledge is more likely to be produced when it undermines or has the potential to undermine beliefs and practices assumed to be fundamental to our nature as humans' (p.479). This in turn creates conditions in which knowledge needs to be hidden to avoid discovery. Thus, while forbidden knowledge may be predominantly explicit, hidden knowledge is by its very nature highly tacit in form.

As a term, hidden knowledge is inextricably linked with notions of 'secret societies', esotericism and conspiracy theories, as von Stuckrad proposes: 'What makes a discourse esoteric is the rhetoric of hidden truth, which can be unveiled in a specific way and established contrary to other interpretations of the universe and history often that of the institutionalised majority' (2016, p.10). However, hidden knowledge is not limited to the occult.

The positioning of hidden knowledge versus established discourse is supported by Dyrendal (2014) who also provides a timely reminder of the relationships between dark knowledge, agency and power: Hidden knowledge about secret agents who are more effective than those seen, also brings in the question of agency, and how secret knowledge may make it more powerful.' Although hidden knowledge is seen as a tool to promote the power of knowledge, and of those who hold it, Livingstone and Sawchuck (2003, p.3) suggest that knowledge may not be purposefully hidden, but in effect 'overlooked' by those in power:

'Knowledge and power are intimately related. The most powerful people - corporate executives, top managers, and professionals - are most likely to have their knowledge and skills institutionally certified and closely linked with opportunities to apply these capabilities. The least powerful people - those hired for an hourly wage and the unemployed - are most likely to have their knowledge and skills institutionally ignored or devalued and to have only more fragmented and submerged chances to apply their capabilities in most paid workplaces or other public settings.'

Similarly, Barkun (2016) uses the term 'stigmatised knowledge' to mean 'knowledge claims that have been ignored or rejected by those institutions we rely upon to validate such claims.' Barkun suggests that one role played by these instititions is to (in effect) grant approval to knowledge claims. However, Barkun notes that ' $[\mathrm{t}]$ hose knowledge claims that have not made the grade acquire a kind of stigma, a disrepute by virtue of their failure to acquire institutional approval.' This concept of stigmatised knowledge can be seen to be closely related to Hanegraaff's (2012) concept of rejected knowledge. Hanegraaff (2012) proposes that esotericism can be 
considered a form of purposefully 'rejected knowledge' due to its rejection of 'normative conceptions of religion, rationality and science'. This perspective echoes our own view of Dark Knowledge as having the potential to marginalise, exclude and isolate and 'other' people or communities who rationalise acceptance of this form of epistemic knowledge and thus set themselves apart from the socially acceptable form of knowledge.

\section{Information, Dark Knowledge and Affordances}

The concept of affordances is also central to our emerging understanding of Dark Knowledge. Affordances represent invitational opportunities (Billett, et al, 2004) that are furnished by the environment or context. Gibson (1979) suggests that affordances focus on the source of information available to people. 'Affordances of the environment are what it offers the animals, what it provides or furnishes, either for good or ill' (Gibson, 1979, p. 27). Consequently, an affordance (whether it is physical, symbolic, or communicative) represents information that is meaningful to an individual or that makes a difference (Lloyd 2010, p.169). Moreover, these invitational qualities are predicated upon an ability to recognize and mediate the information environment and construct information landscapes (Lloyd, 2006). Affordances therefore, furnish an opportunity that enable information to be become operationalized, e.g., contingent forms of embodied knowledge that only be knowable in the moment of practice. This perspective clearly resonates with the argument made earlier in this paper regarding the fleeting and unstable nature of Dark Knowledge.

An explanation for how knowledge can be either hidden in plain sight or in tacit forms can be found in the link between the Bateson's (1972) view of information and Gibson's (1979) view of affordances. Bateson describes information as 'any difference which makes a difference in some later event' (Bateson, 1972, p.323 p.386). This abstract and open-ended understanding conceptualizes information as a bit or an idea, which when accessed can make a difference to the user. To make a difference, implies change to ways of knowing, and types of knowledge, which may be positive, negative or neutral (Lloyd 2017). For example, the development of chemical weapons such as those used in the Tokyo subway attack was not reliant on understanding of chemicals or equipment purposefully intended for malicious use: 'Chemical and biological weapons, on the other hand, are cheap and easy to build using equipment and materials that are used extensively for a host of civilian purposes. This was demonstrated all too clearly in March 1995 when terrorists released chemical weapons on the Tokyo subway.' (Lyell, 1996)

By our account, Dark Knowledge represents a version or interpretation of reality and associated discourses which may be understood as different from normative epistemologies (i.e. on moral or ethical grounds). This knowledge may reside in the margins of a society or situation and create the conditions for a different epistemological view of knowledge and ways of knowing. For example, from previous research we know that refugee communities in Europe make use of Whatsapp to exchange knowledge (Di Giovanni et al, 2013). By using Whatsapp, these communities can 'hide' their explicit knowledge, contained within the application itself): 'Whatsapp has a comparative advantage of allowing its users to exchange instant messages at a significantly lower marginal cost than other mobilebased text messaging services. In addition to low cost, Whatsapp messages are 
difficult to track thus considered a secured platform of communication among a large bunch of Syrian refugees. As a result, Syrian activists and refugees rely heavily on Whatsapp for coordination and planning for meetings away from government's surveillance software.' (Di Giovanni et al, 2013, p.12).

\section{Information Landscapes, Desire Lines and Dark Knowledge}

To frame this conceptualisation of Dark Knowledge, we also draw from the concept of information landscapes (Lloyd 2006) and desire lines (Burnett and Lloyd 2019). We posit the existence of desire lines 'as a representation of an intended and purposeful direction of travel which does not employ formally managed or directed routes across a landscape, but is reliant on the complimentary relationships between people and their environments which furnishes affordances described as opportunities for people to interact' (Burnett \& Lloyd, 2019, np).

Information landscapes are constructed and shaped through people's constructions of their interaction with information environments. Information landscapes reference sites of knowledge and ways of knowing that are central to agency. In our current conception, an information landscape may be composed of both light and dark knowledges which allows people to operate in different contexts. In the construction of information landscapes, people may take less obvious or formalised paths to the information required (i.e. they may not search or seek information in expected or designated ways). By deviating from establish pathways or in seeking Dark Knowledge (which resides outside societal norms) people potentially create desire lines which trace their travel across information environments, but away from normative paths, nodes and edges. Desire lines may not be formalised but reference individual agency (to resist a formal path) and are therefore subject to cultural and social considerations.

For example, the moral complexity of the relationships between Light and Dark Knowledge can be highlighted in the ongoing debates surrounding the use of knowledge derived from the horrific medical experiments conducted by the Nazis during World War Two, including experiments into hypothermia. Cohen (1990) presents a highly polarising situation, which on one hand argues that 'use of the data would serve as a lesson to the world, that the victims did not die futilely, and that a post mortem use of the data would retroactively give "purpose" to their otherwise meaningless deaths.' Conversely, he also states 'Lord Immanuel Jakobovits, Chief Rabbi of the British Commonwealth of Nations and the pioneer of Jewish Medical Ethics, said that using the Nazi data offers not a shred of meaning to the $6,000,000$ deaths. In fact, use of the data would serve to dishonour them even more so.'

The moral and ethical positioning of white and black hat hackers provides an additional opportunity to highlight the dualistic nature of the application of knowledge. Black and white hat hackers are distinguished by the purpose of their hacking activity and whether consent has been provided (Hatfield, 2019), however both start with the same potential aim to compromise a system and gain entry. White hat's hacking is generally viewed ethically motivated with the aim of identifying vulnerabilities in the security of a system and occurs when consent is given., e.g. penetration testing used in the banking industry to identify potential weaknesses in the network. Black hats represent the binary of this classification representing the 
unlawful entry of networks with malicious intent, and/theft of information or financial gain (Hatfield, 2019). Both categories of hackers will develop the same knowledge (about breaching networks, etc) however, the application of the knowledge will differ. In effect therefore we can consider white hat hackers as knowledge workers, and black hat hackers as dark knowledge workers.

Desire lines may exist below the visible information landscape as evidenced by the use of the 'dark web', an unindexed part of the 'deep web' which has been related to hacking, pornography and drug dealing, and in relation to refugees, human trafficking. Thus, desire lines may provide routes, not only between formal and informal information nodes, but between knowledge objects present (both tacitly and explicitly) of Dark Knowledge addressing personal and societal needs which cross barriers of legality and legitimacy.

We can consider the explicit raising of these issues (albeit in covert forums) as paths, in that they provide hidden information about routes for others to follow in both a physical and virtual sense. As such, these contexts may also be considered to be information landscapes themselves. We propose that all information landscapes have the potential to comprise a binary Dark/Light Knowledge dimension, and that desire lines may be used to aid in finding and using Dark Knowledge.

\section{[INSERT FIGURE 3 HERE]}

\section{Figure 3: Information landscape- referencing light and Dark Knowledge, socially ethically contested space and sites of resolution/agency and performance.}

In this diagram, an information landscape is composed of dark and light knowledge which must resolved (decided upon) creating social/ ethically enacted space and producing sites of resolution. Sites of resolution reference how agency and performance are controlled by actors. In simple terms, people decide what knowledge to use, and then resolve how to openly use it (or to hide it). This knowledge is judged by others/ individuals, etc. While the diagram represents dark and light knowledge together, it may be that information landscapes may only be shaped through dark knowledges or light knowledges or a combination of both, i.e. use normative and nonnormative knowledges.

\section{Characteristics and Conclusions}

Thus far in our discussion, we have posited Dark Knowledge as knowledge which deviates from, and exists outside societal norms, referencing hidden and forbidden characteristics. Therefore, we can suggest that we can see the applications of Dark Knowledge (in action and interaction) more readily than we can observe Dark Knowledge itself. In this regard, Dark Knowledge is like the wind - we can identify and observe its effects on its environment. This in turn makes the debate surrounding the characteristics of Dark Knowledge highly subjective, and we readily acknowledge that there are shades of grey around this topic, and that there are questions around normative values applied by society. We acknowledge that Dark Knowledge has both ontological and epistemological dimensions which need deep analysis to contribute to further conceptualisation. 
Bearing these points in mind, at this emerging stage of our conceptualisation, we suggest that Dark Knowledge has several key characteristics (Table 2). These are not exhaustive, and we anticipate that these will be refined as the work in this area continues to develop. These characteristics also reflect the key elements of Dark Knowledge which we have identified and discussed previously.

\section{[INSERT TABLE 2 HERE]}

\section{Table 2: Characteristics of Dark Knowledge}

To summarise our key points, Dark Knowledge may be considered by society to be knowledge that deviates from societal norms, and may pose a danger to the moral or physical conditions of everyday life. Given the forbidden nature of Dark Knowledge, it is not shared freely, and access to it may be limited via personal interactions with the knowledge holder(s), or via membership of a specific group. For example, access to content on the Dark Web may be limited via permissions, software or encryption.

While knowledge itself may be ethically neutral, the application of that knowledge may be questionable or even illegal. For example, knowing how to break into a property is not an issue in itself, until that knowledge is operationalised. Given the hidden and forbidden aspects of Dark Knowledge, we propose that Dark Knowledge may be tacit in nature to avoid discovery. For example, knowledge of how to secure the services of a human trafficker may be undocumented, or obfuscated to avoid detection via use of nicknames, false addresses, etc. Dark Knowledge is, perhaps unsurprisingly, difficult to identify and locate, particularly when it may exist in a tacit form. A possible exception to this characteristic is Dark Knowledge in explicit forms, such as forbidden texts.

The cost of accessing Dark Knowledge is inevitably linked to its availability, exclusivity and legality. Given this, Dark Knowledge may be costly to acquire (financially, socially or morally), and indeed may lead users to become indebted to its providers. For example, securing access to human trafficking rings to arrange travel between countries. The fleeting and temporally unstable nature of Dark Knowledge further adds to its impermanent nature, facilitating difficulty in its identification and use. Lastly, as has been seen in a large number of cases involving refugees and human traffickers, the application of Dark Knowledge may be dangerous to life.

All knowledge and the agency it shapes may be viewed as inherently situationally dependent. That is, it depends entirely on the context and methods by which knowledge has been acquired, and how it may be applied whether it might be considered as personally or societally beneficial, neutral or detrimental. Naturally, the societal perspective on the neutrality (or otherwise) of knowledge is in itself fluid. We can therefore adopt a view on 'Dark Knowledge' by its societal positioning within governmental and legal constructs.

In this paper we have presented what we hope will be the beginning of a new conceptualisation of knowledge. We have presented the background to the topic by highlighting the rise in interest around 'dark' topics. However, we have tried to emphasise that Dark Knowledge is not in itself malignant. Instead, we have proposed that Dark Knowledge may be defined by two elements: that it may be hidden and /or 
forbidden. We have identified a number of characteristics which we hope will aid in the identification of Dark Knowledge, and in further explorations of this topic.

Our engagement with Dark Knowledge is intended to provide an access point to a new perspective on the moral and ethical dimensions which may surround knowledge and its usage. By presenting examples in which Dark Knowledge may exist and indeed play a critical role, we have tried to emphasise its significance, despite our acknowledged difficulties in identifying its location or existence.

For information studies, Dark Knowledge may impact in a range of different ways. We have shown that Dark Knowledge may been gained through morally corrupt means, and that consequently may present ethical issues with regard to collections management. Dark knowledge may also be acquired in ways which are morally ambiguous, so the application of dark knowledge informs both our understanding of knowledge-based processes, and the interactions between knowledge acquisition and application.

As we have shown, these debates are far from static, and will continue to evolve as ethical and moral stances continue to shift. Our role as information researchers, custodians and curators of content obliges us to consider these issues carefully. We cannot and should not simply detach ourselves from these challenging issues, and this paper has purposely raised these to open up a debate around these (and other relevant) issues, to inform practice and theory. 


\section{References}

Alter, Steven (2014), "Theory of Workarounds", Communications of the Association for Information Systems, Vol. 34 Article 55, pp. 1041-1066.

Balan, A.K., Rathod, V., Murphy, K.P. and Welling, M. (2015), "Bayesian dark knowledge", in Advances in Neural Information Processing Systems (pp. 34383446), available at: http://papers.nips.cc/paper/5965-bayesian-dark-knowledge.pdf (accessed 12 March 2020).

Bancroft, A. and Reid, P.S. (2016), "Concepts of illicit drug quality among darknet market users: Purity, embodied experience, craft and chemical knowledge”, International Journal of Drug Policy, Vol. 35, pp.42-49.

Barkun, M. (2016). Conspiracy theories as stigmatized knowledge. Diogenes, p.1-7. https://doi.org/10.1177/0392192116669288

Baskin, W. (2015), Dictionary of Satanism, Open Road Media, New York, NY.

Bateson, G. (1972), Steps to an ecology of mind: Collected essays in anthropology, psychiatry, evolution, and epistemology, University of Chicago Press, Chicago.

Batory, D., Gonçalves, R., Marker, B. and Siegmund, J. (2013), "Dark knowledge and graph grammars in automated software design" in International Conference on Software Language Engineering (pp. 1-18) in Indianapolis, IN, USA, available at: https://link.springer.com/chapter/10.1007/978-3-319-02654-1_1 (accessed 17 February, 2020)

Bauer, C.P. (2013), Secret history: The story of cryptology. CRC Press, Florida.

Baxter, I.D. (1992), "Design maintenance systems", Communications of the $A C M$, Vol.35 No.4, pp.73-90.

Berger, P.L. and Luckmann, T. (1991), The social construction of reality: A treatise in the sociology of knowledge. Penguin, UK.

Billett, S., Barker, M. and Hernon-Tinning, B. (2004), "Participatory practices at work", Pedagogy, Culture and Society, Vol. 12 No. 2, pp. 233-57.

Blackler, F. (1995), "Knowledge, knowledge work and organizations: An overview and interpretation", Organization studies, Vol.16 No 6, pp.1021-1046.

Bonner, A. \& Lloyd, A. (2011), "What information counts at the moment of practice? Information practices of renal nurses", Journal of Advanced Nursing, Vol 67 No 6, pp. 1213-1221.

Burnett, S. \& Lloyd, A. (2019). "The road not taken: locating desire lines across information landscapes", in Proceedings of CoLIS, the Tenth International Conference on Conceptions of Library and Information Science, Ljubljana, Slovenia, 
June 16-19, 2019. Information Research, 24(4), paper colis1911, available at: http://InformationR.net/ir/24-4/colis/colis1911.html (accessed 9 April 2020).

Chatman, E.A. (1996), "The impoverished life-world of outsiders". Journal of the American Society for Information Science, Vol. 47 No. 3, pp.193-206.

Chen, H. (2011), Dark web: Exploring and data mining the dark side of the web, Springer Science \& Business Media, New York, NY.

Chen, H., Chung, W., Qin, J., Reid, E., Sageman, M. and Weimann, G. (2008), "Uncovering the dark Web: A case study of Jihad on the Web", Journal of the American Society for Information Science and Technology, Vol. 59 No.8, pp.13471359.

Cohen, B. (1990), "The ethics of using medical data from Nazi experiments", Journal of Halacha and Contemporary Society, Spring, No. 19, pp.103-126.

Dervin, B. (1976), "Strategies for dealing with human information needs: Information or communication?”, Journal of Broadcasting \& Electronic Media, Vol. 20 No.3, pp.323-333.

Dyrendal, A. (2014), "Hidden Knowledge, Hidden Powers: Esotericism and Conspiracy Culture", in Asprem, E. and Granholm, K. (Eds.), Contemporary Esotericism, Routledge, Milton Park, pp. 210-235.

Emil, G.U.I.A.Ș. and Mihaela, H.C. (2019), "The Underground Economy:

Components", Annals of the University of Oradea, Economic Science Series, Vol. 28 No.1, p.380.

Foucault, M. (2012), Discipline and punish: The birth of the prison, Vintage, New York, NY.

Foucault, M. (2005), The order of things, Routledge, Milton Park.

Gibson, J. J. (1979), The Ecological Approach to Visual Perception, Houghton Mifflin, Boston.

Di Giovanni, J., Fisher, N., Shajrawi, M., Madi, A., Nova, K. and Tzatzev, A. (2013), "Lost: Syrian refugees and the information gap", Internews, available at: www.internews.org/sites/default/files/resources/Internews_Lost_SyriaReport_Nov20 13 _web.pdf (accessed 4 November 2019).

Griffin, R.W., O'Leary-Kelly, A. and Pritchard, R.D. (2004). The dark side of organizational behavior (pp. 23-61). San Francisco, CA: Jossey-Bass.

Hanegraaff, Wouter (2012), Esotericism and the Academy: Rejected Knowledge in Western Culture, Cambridge University Press, Cambridge.

Hatfield, J. M. (2019), "Virtuous human hacking: The ethics of social engineering in penetration-testing", Computers \& Security, No. 83, pp. 354-366. 
Hinton, G., Vinyals, O. and Dean, J. (2015), Distilling the knowledge in a neural network. arXiv preprint arXiv:1503.02531, available at:

https://arxiv.org/pdf/1503.02531.pdf (accessed 7 April 2020).

Jardine, E. 2018. "Privacy, censorship, data breaches and Internet freedom: The drivers of support and opposition to Dark Web technologies", new media \& society, Vol. 20 No. 8, pp.2824-2843.

Jeschke, Jonathan M., Lokatis, S., Bartram, I. and Tockner, K. (2019) "Knowledge in the dark: scientific challenges and ways forward." FACETS No. 4 pp. 423-441.

Johnson, Deborah G. (1996) "Forbidden Knowledge and Science as Professional Activity”, The Monist, Vol. 79, No 2, pp. 197-217.

Kari, J. and Hartel, J. (2007), "Information and higher things in life: Addressing the pleasurable and the profound in information science", Journal of the American Society for Information Science and Technology, Vol. 58 No. 8, pp.1131-1147.

Kempner, J., Merz, J.F. and Bosk, C.L. (2011) "Forbidden Knowledge: Public Controversy and the Production of Nonknowledge", Sociological forum, Vol. 26, No. 3, pp. 475-500.

Kempner, J., Perlis, C.S. and Merz, J.F. (2005), "Forbidden knowledge”, Science, Vol. 307 No. 5711, pp.854-854.

Linstead, S., Maréchal, G. and Griffin, R.W. (2014), "Theorizing and researching the dark side of organization”, Organization Studies, Vol. 35 No. 2, pp.165-188.

Livingstone, D.W. and Sawchuk, P.H. (2003), Hidden knowledge: Organized labor in the information age. Rowman \& Littlefield, Washington DC.

Lloyd, A. (2006), "Information literacy landscapes: an emerging picture", Journal of documentation, Vol. 62 No. 5, pp. 570-583.

Lloyd, A. (2014), "Following the red thread of information in information literacy research: Recovering local knowledge through interview to the double", Library \& Information Science Research, Vol.36 No. 2, pp. 99-105.

Lloyd, A. (2017), "Researching fractured (information) landscapes: Implications for library and information science researchers undertaking research with refugees and forced migration studies", Journal of Documentation, Vol. 73 No. 1, pp. 35-47.

Lyell, L. (1996), "Chemical and Biological Weapons: The Poor Man's Bomb", available at: https://fas.org/irp/threat/an253stc.htm (accessed 4 April 2020).

Martzoukou, K. and Burnett, S., 2018. "Exploring the everyday life information needs and the socio-cultural adaptation barriers of Syrian refugees in Scotland", Journal of Documentation, Vol. 74 No. 5, pp.1104-1132. 
Mayer, J. (2017), Dark money: The hidden history of the billionaires behind the rise of the radical right, Anchor Books, New York, NY.

Nonaka, I. and Takeuchi, H. (1995), The Knowledge-Creating Company, Oxford University Press, Oxford.

Polanyi, M. (1966), The Tacit Dimension. Routledge and Kegan Paul, London.

Powell, W. (1971), The Anarchist Cookbook, Lyle Stuart. Inc., New York, NY.

Reber, A. (1995), Implicit Learning and Tacit Knowledge: An Essay on the Cognitive Unconscious. Oxford University Press, Oxford.

Rehmann-Sutter, C. (1996), “Frankensteinian Knowledge?” The Monist, Vol. 79 No. 2, pp. 264-279.

Shattuck, R. (1996), Forbidden Knowledge: From Prometheus to Pornography, Harcourt Brace, New York, NY.

Smith, D.J. (2004), The Shipman Inquiry, The Stationery Office, London.

Smith, David Livingstone (2018) “Dark Knowledge?”, available at:

https://www.philosophytalk.org/blog/dark-knowledge (accessed 12 October 2019).

Stadtwald, M. (2016), "Gandalf and Guardini: A Fresh Look at the Theology of J.R.R. Tolkein's The Lord of the Rings", available at: https://digitalcommons.augustana.edu/celebrationoflearning/2016/presentations/13 (accessed January 18 2020).

Tandoc Jr, E.C., Lim, Z.W. and Ling, R. (2018), "Defining “fake news": a typology of scholarly definitions". Digital journalism, Vol. 6, No 2, pp.137-153.

Von Stuckrad, K., (2016), Western esotericism: a brief history of secret knowledge. Routledge, London.

Weiss, B. (2018), "Meet the renegades of the Intellectual Dark Web", The New York Times, 18 May, available from:

https://www.nytimes.com/2018/05/08/opinion/intellectual-dark-web.html (accessed 8 April 2020).

Werhane, P.H. (1989) “The ethics of insider trading”, Journal of Business Ethics, Vol. 8, pp. 841-845.

West, N. (2016), Spycraft Secrets: An Espionage A-Z. The History Press, Cheltenham.

Wood, D.M. (2007), "Beyond the panopticon? Foucault and surveillance studies”, Elden, S. (Ed.), Space, knowledge and power: Foucault and geography, Routledge, Milton Park, pp. 245-263. 
Zins, C. (2007), "Conceptual approaches for defining data, information, and knowledge", Journal of the American society for information science and technology, Vol. 58 No. 4, pp.479-493. 


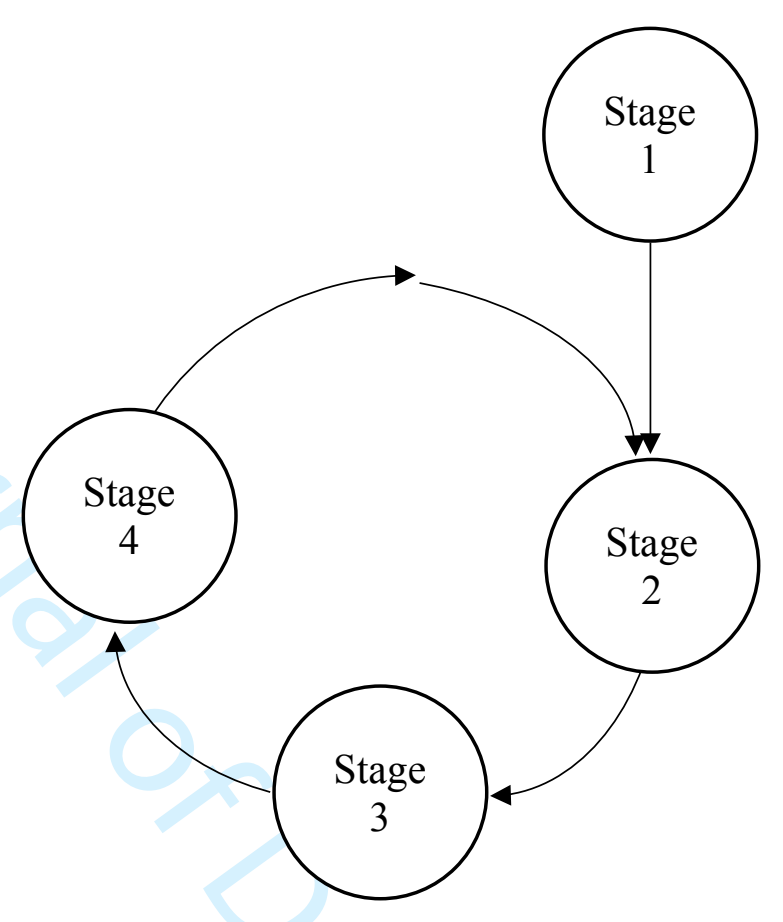

Figure 1: Literature search process 


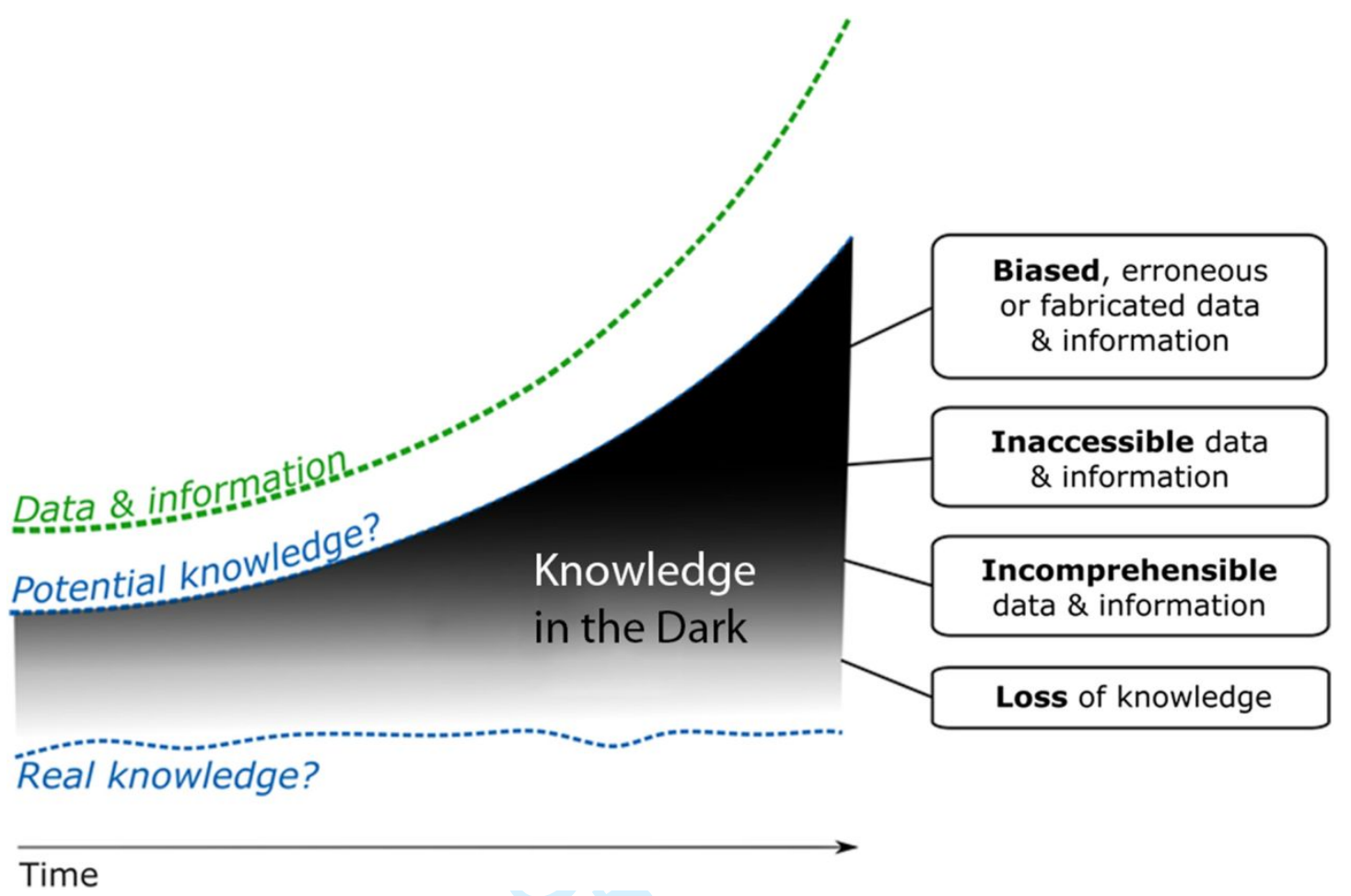

Figure 2: Knowledge in the Dark (Jeschke et al (2019))

[Please note, Figure 2 is available via a creative commons license (Attribution 4.0 International (CC BY 4.0)] 
Figure 3: Information landscape- referencing light and Dark Knowledge, socially ethically contested space and sites of resolution/agency and performance.

\section{Light Knowledge}

Deviates from society norms, may be hidden or forbidden-
Conforming to societal norms 


\begin{tabular}{|l|l|l|l|}
\hline Dark Knowledge & Hidden Knowledge & Forbidden Knowledge & Secret Knowledge \\
\hline Esoteric* & Conspiracy Theor* & Hack* & Censorship \\
\hline Dark Web & $\begin{array}{l}\text { Rejected } \\
\text { Knowledge }\end{array}$ & Workaround* & Spycraft \\
\hline $\begin{array}{l}\text { Negative } \\
\text { Knowledge }\end{array}$ & Non-Knowledge & Agnotolog* & $\begin{array}{l}\text { Stigmati*ed } \\
\text { Knowledge }\end{array}$ \\
\hline
\end{tabular}

\section{Table 1: Key search terms}




\begin{tabular}{|l|l|l|}
\hline Characteristics of Dark Knowledge & Forbidden & Hidden \\
\hline $\begin{array}{l}\text { Dangerous/ deviant knowledge (Chen et al, 2008; } \\
\text { Shattuck, 1996; Griffin and O'Leary-Kelly, 2004; } \\
\text { Kempner, Merz and Bosk, 2011) }\end{array}$ & $\mathrm{x}$ & \\
\hline $\begin{array}{l}\text { Prohibited by divine, religious, moral, or secular authority } \\
\text { (Shattuck, 1996) }\end{array}$ & $\mathrm{x}$ & \\
\hline Inaccessible / unattainable (Shattuck, 1996) & $\mathrm{x}$ & \\
\hline Fragile / delicate (Shattuck, 1996) & $\mathrm{x}$ & \\
\hline Double-bound (Shattuck, 1996) & $\mathrm{x}$ & \\
\hline Ambiguous (Shattuck, 1996) & $\mathrm{x}$ & \\
\hline Marginalising, 'othering' (Chatman, 1996) & $\mathrm{x}$ & $\mathrm{x}$ \\
\hline Transformative (Johnson, 1996) & $\mathrm{x}$ & $\mathrm{x}$ \\
\hline Consequentialist (Johnson, 1996) & & $\mathrm{x}$ \\
\hline Invitational (Lloyd, 2006) & & $\mathrm{x}$ \\
\hline Non-normative (Lloyd, 2014) & & $\mathrm{x}$ \\
\hline Fleeting/ unstable (Batory et al, 2013) & $\mathrm{x}$ \\
\hline Highly tacit (Batory et al, 2013) & & $\mathrm{x}$ \\
\hline Highly contextual (Martzoukou and Burnett, 2018) & $\mathrm{x}$ \\
\hline Power promoting (Dyrendal, 2014) & & $\mathrm{x}$ \\
\hline Stigmatising/rejected (Barkun, 2016; Hanegraaff (2012) & & \\
\hline Overlooked (Livingstone and Sawchuck, 2003) & & \\
\hline
\end{tabular}

Table 2: Characteristics of Dark Knowledge 